\title{
Modeling for Simple Batch Distillation of Vanadium Oxychloride-Titanium Tetrachloride $\left(\mathrm{VOCl}_{3}-\mathrm{TiCl}_{4}\right)$ Mixture
}

\author{
Tran Duy Hai ${ }^{1,2}$, Tran Anh Khoa ${ }^{1,2^{*}}$, Minh-Vien Le ${ }^{2,3}$, Mai Thanh Phong ${ }^{2,3}$, Phan Dinh Tuan ${ }^{1}$ \\ ${ }^{1}$ Ho Chi Minh City University of Natural Resources and Environment, Ho Chi Minh City 700000, Vietnam \\ ${ }^{2}$ Faculty of Chemical Engineering, Ho Chi Minh City University of Technology (HCMUT), Ho Chi Minh City 700000, \\ Vietnam \\ ${ }^{3}$ Vietnam National University Ho Chi Minh City, Ho Chi Minh City 700000, Vietnam
}

Corresponding Author Email: takhoa@hcmunre.edu.vn

https://doi.org/10.18280/ijht.390614

Received: 9 November 2021

Accepted: 23 December 2021

\section{Keywords:}

distillation, modeling, titanium tetrachloride, vanadium oxychloride

\begin{abstract}
$\mathrm{VOCl}_{3}$ and $\mathrm{TiCl}_{4}$ exhibit a similarity of various thermal properties, causing difficulty for these components separation through distillation technique. Dynamic behavior of distillation process of $\mathrm{VOCl}_{3}-\mathrm{TiCl}_{4}$ mixture was modeled based on the mass and energy balances, revealing in a model form of the ordinary differential equations. Influences of heating power, airflow, initial concentration, and operating pressure were considered. Simulation results show an ineffective distillation of the mixture under natural pressure. However, the reduction of the operating pressure advanced the pure $\mathrm{TiCl}_{4}$ recovery performance. Compared to experimental data, the relative error of the simulation findings is less than $5 \%$, indicating the potential of the application of the proposed model for describing the distillation of the $\mathrm{VOCl}_{3}-\mathrm{TiCl}_{4}$ mixture.
\end{abstract}

\section{INTRODUCTION}

Titanium and its compounds have been widely used in aerospatiale, automotive and biomedical engineering because of specific physicochemical properties such as high mechanical strength, good corrosive resistance, and biocompatibility [1-3]. Natural minerals (ilmenite, rutile, anatase, leucoxene, and brookite) and concentrated sources (titania slag and synthetic rutile) are used as titanium-bearing feedstocks for titanium processing $[4,5]$. Until now, metallic titanium and high-grade $\mathrm{TiO}_{2}$ were mainly produced from titanium tetrachloride $\left(\mathrm{TiCl}_{4}\right)$ - a product of chlorination of titanium sources [6]. However, impurities in raw material, were also chlorinated to the chloride compounds, result in a color change of crude $\mathrm{TiCl}_{4}$ from yellow to dark reddishbrown [7, 8].

Physical, chemical and physo-chemical methods were successfully conducted for purifying $\mathrm{TiCl}_{4}$ with high efficiency $[7,9]$. In terms of them, distillation is a powerful technique toward industrial application due to its low cost and controllability $[9,10]$. Because of the small difference between the normal boiling point of vanadium oxychloride $\left(\mathrm{VOCl}_{3}\right)\left(127^{\circ} \mathrm{C}\right)$ and the desired $\mathrm{TiCl}_{4}$ product $\left(136.5^{\circ} \mathrm{C}\right)$, the removal of $\mathrm{VOCl}_{3}$ through distillation is ineffective [9]. However, the purity of product and the recovery yield of distillation can be controlled and optimized by changing distillation mode and operating conditions [11]. Using modeling and simulation, the instinct properties of many engineering problems under different setup values of variables can be quickly and simply explored [12]. To our best knowledge, the modeling of $\mathrm{VOCl}_{3}-\mathrm{TiCl}_{4}$ distillation has not been reported. In this paper, the dynamic behavior of $\mathrm{VOCl}_{3}-\mathrm{TiCl}_{4}$ mixture separation in a simple batch distillation column was modeled. The comparison between experimental and simulated results was also presented.

\section{THE EQUATIONS}

The scheme of the studied batch distillation system is shown in Figure 1, including a bottom (boiler), a condenser, and a distillation column, which was cooled by outer airflow under forced convection. Assumptions were considered for modeling: (i) negligible temperature change in a cross-section of the distillation column, (ii) equilibrium of heat exchange through the distillation column and heat of condensation of the heavy component $\left(\mathrm{TiCl}_{4}\right)$, and (iii) small mole fraction of $\mathrm{VOCl}_{3}$ in feedstock.

The heating stage of bottom mixture up to the boiling point of the light component $\left(\mathrm{VOCl}_{3}\right)$ was ignored. The models were established for the following stage since the temperature at the top of the distillation column has reached the boiling point of $\mathrm{VOCl}_{3}$ until the liquid in the bottom was completely evaporated.

\subsection{Modeling for the distillation column}

Mathematical models are based on heat and mass balances of a differential volume of the distillation column with a height $d z$ between $z$ and $(z+d z)$, as shown in Figure 2 .

$$
m_{a} c_{p, a} d \theta=2 \pi h R\left(T_{z}-\theta\right) d z
$$

where, $m_{a}$ and $c_{p . a}$ is mass flow $\left(\mathrm{kg} . \mathrm{s}^{-1}\right)$ and constant pressure heat capacity $\left(\mathrm{J}_{\mathrm{kg}} \mathrm{kg}^{-1} \cdot \mathrm{K}^{-1}\right)$ of air, $h$ is convective heat transfer coefficient $\left(\mathrm{W} \cdot \mathrm{m}^{-2} \cdot \mathrm{K}^{-1}\right), R$ is the radius of the distillation 
column (m), $T_{z}$ is the temperature of the fluid inside the distillation column $\left({ }^{\circ} \mathrm{C}\right), \theta$ and $d \theta$ is temperature and temperature change of air $\left({ }^{\circ} \mathrm{C}\right), z$ is distance from the bottom of distillation column to the differential volume.

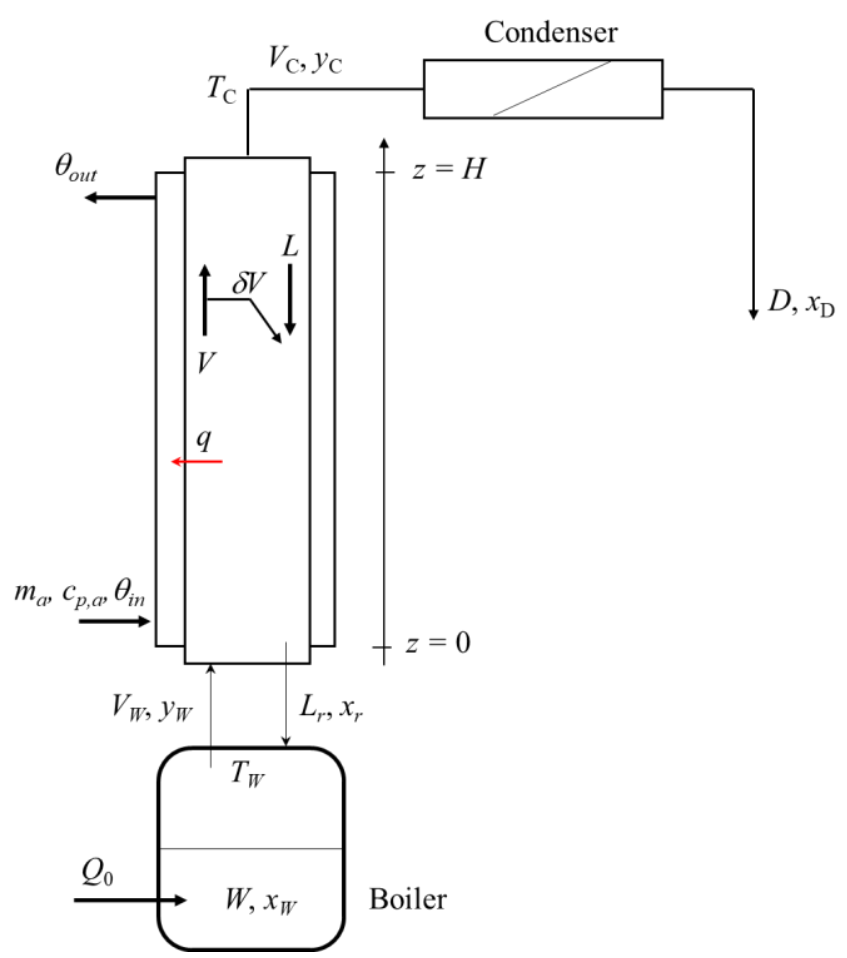

Figure 1. Scheme of the batch distillation column

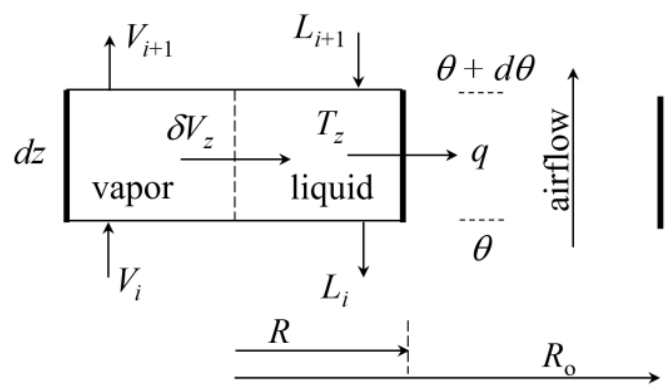

Figure 2. Differential volume of the distillation column

Re-arranging, Eq. (1) can be written as:

$$
m_{a} c_{p, a} d \theta=2 \pi h R\left(T_{z}-\theta\right) d z
$$

Integrating (2) from $z=0\left(\theta=\theta_{\text {in }}\right)$ :

$$
\int_{\theta_{i n}}^{\theta} \frac{d \theta}{T_{z}-\theta}=\frac{2 \pi h R}{m_{a} c_{p, a}} \int_{0}^{z} d z
$$

The temperature of the air as a function of distillation column height was carried out:

$$
\theta=T_{z}-\left(T_{z}-\theta_{i n}\right) e^{-\beta z}
$$

where, $\beta=\frac{2 \pi h R}{m_{a} c_{p, a}}\left(\mathrm{~m}^{-1}\right)$.

At $z=H$, the outlet temperature of the air, $\theta_{\text {out }}$, is,

$$
\theta_{\text {out }}=T_{\mathrm{C}}-\left(T_{\mathrm{C}}-\theta_{\text {in }}\right) e^{-\beta H}
$$

where, $T_{\mathrm{C}}$ is the temperature at the top of the distillation column $\left({ }^{\circ} \mathrm{C}\right)$.

Total exchanged heat $Q(\mathrm{~W})$ through the distillation column can be calculated by (6).

$$
Q=m_{a} c_{p, a}\left(\theta_{\text {out }}-\theta_{\text {in }}\right)
$$

Substituting (5) into (6), the final expression for the total transferred heat was obtained.

$$
Q=m_{a} c_{p, a}\left(T_{C}-\theta_{i n}\right)\left(1-e^{-\beta H}\right)
$$

It notes that the released heat from the condensation of vapor in the distillation column was assumed to be transferred to outer airflow. Therefore, the total mole of the condensed vapor, $\delta V_{\Sigma}$, is:

$$
\delta V_{\Sigma}=\frac{Q}{\lambda}=\frac{m_{a} c_{p, a}}{\lambda}\left(T_{C}-\theta_{i n}\right)\left(1-e^{-\beta H}\right)
$$

where, $\lambda$ is the heat of condensation $\left(\mathrm{J} \cdot \mathrm{mol}^{-1}\right)$. Eq. (9) was also obtained.

$$
\delta V_{\Sigma}=L_{r}
$$

where, $L_{r}$ is the liquid flow returned from the distillation column to the bottom (mol.s $\left.\mathrm{s}^{-1}\right)$.

To separate $\mathrm{VOCl}_{3}$ (light component) from the $\mathrm{VOCl}_{3}-\mathrm{TiCl}_{4}$ mixture by distillation technique, the expected temperature at the top of the distillation column was equal to the boiling point of $\mathrm{VOCl}_{3}$. In addition, the mole fraction of $\mathrm{VOCl}_{3}$ in the feedstock was considered in a low range. Therefore, the condensation process, occurred in the distillation column, can be only considered for $\mathrm{TiCl}_{4}$ (the heavy component). It means that the heat of $\mathrm{TiCl}_{4}$ condensation, $\lambda_{2}$, was substituted to the value $\lambda$ in (8).

\subsection{Modeling for the boiler}

Eq. (10) presents the energy balance for the boiler.

$$
\frac{d\left(W h_{W}^{l i q}\right)}{d t}=Q_{0}-V_{W} h_{W}^{v a p}+L_{r} h_{r}^{\text {liq }}
$$

where, $h_{W}^{\text {liq }}$ and $h_{W}^{\text {vap }}$ are the enthalpy of the liquid and vapor phase in the bottom $\left(\mathrm{J} \cdot \mathrm{mol}^{-1}\right), Q_{0}$ is heating power $(\mathrm{W}), W$ is the liquid amount in the bottom (moles), $V_{w}$ is vapor flow moved from the bottom up the distillation column $\left(\mathrm{mol} . \mathrm{s}^{-1}\right)$, $h_{r}^{l i q}$ is the enthalpy of the returned liquid flow $\left(\mathrm{J} \cdot \mathrm{mol}^{-1}\right)$.

Because $\mathrm{VOCl}_{3}$ was in a low mole faction, it can apply approximate equation (11).

$$
h_{W}^{l i q} \approx h_{r}^{l i q} \approx h_{2}^{l i q}
$$

where, $h_{2, W}^{l i q}$ is the enthalpy of $\mathrm{TiCl}_{4}$ liquid $\left(\mathrm{J} \cdot \mathrm{mol}^{-1}\right)$ at the bottom temperature

As consequently, Eq. (10) can be written as: 


$$
h_{2, W}^{l i q} \frac{d W}{d t}=Q_{0}-V_{W} h_{W}^{v a p}+L_{r} h_{2, W}^{l i q}
$$

The mass balance equation for the bottom is represented as (13).

$$
\frac{d W}{d t}=-V_{W}+L_{r}
$$

Combining (13) and (12), the boiler dynamic is represented in (14),

$$
\frac{d W}{d t}=\frac{-Q_{0}}{h_{W}^{v a p}-h_{2, W}^{\text {liq }}}+L_{r}
$$

And, Eq. (15) was also carried out.

$$
V_{W}=\frac{Q_{0}}{h_{W}^{v a p}-h_{2, W}^{l i q}}
$$

Mass balance for $\mathrm{VOCl}_{3}$ component reveals (16).

$$
\frac{d W x_{W}}{d t}=-V_{W} y_{W}+L_{r} x_{r}
$$

where, $y_{W}$ is the mole fraction of $\mathrm{VOCl}_{3}$ vapor in the vapor flow $V_{W}$ (dimensionless), $x_{W}$ and $x_{r}$ is the mole fraction of $\mathrm{VOCl}_{3}$ liquid in the bottom and the returned liquid flow $L_{r}$ (dimensionless).

Due to the vapor-liquid equilibrium in the bottom, the value of $x_{r}$ can approximate to $x_{W}$. Then, Eq. (17) was obtained by applying the partial differentiation rule for (16).

$$
x_{W} \frac{d W}{d t}+W \frac{d x_{W}}{d t}=-V_{W} y_{W}+L_{r} x_{W}
$$

Substituting (13) and (15) into (17), the dynamic model of the $\mathrm{VOCl}_{3}$ component can be described by the differential Eq. (18).

$$
\frac{d x_{W}}{d t}=\frac{Q_{0}}{W\left(h_{W}^{v a p}-h_{2, W}^{\text {liq }}\right)}\left(x_{W}-y_{W}\right)
$$

\subsection{Convective heat transfer coefficient}

In term of estimating the heat transfer coefficient of air for particularly forced convection, $h$, the dimensionless correlation of Nusselt number $(\mathrm{Nu})$, including Reynold number ( $\mathrm{Re}$ ) and Prandtl number (Pr), was considered. For Pr $>0.7$, the empirical correlation (19), well known as Hilpert correlation [13], has been widely accepted. Definitions of $\mathrm{Nu}$ and Re are shown as (20) and (21), respectively.

$$
\mathrm{Nu}=C \operatorname{Re}^{m} \operatorname{Pr}^{1 / 3}
$$

where, $C=0.683, m=0.466$ for $40<\operatorname{Re}<4,000$, and $C=0.193$, $\mathrm{m}=0.618$ for $4,000<\operatorname{Re}<40,000$ [4].

$$
\mathrm{Nu}=\frac{h \cdot D_{h}}{k}
$$

$$
\operatorname{Re}=\frac{u \cdot D_{h}}{v}
$$

where, $D_{h}=2\left(R_{\mathrm{o}}-R\right)$ is the hydraulic diameter $(\mathrm{m}), k$ is the thermal conductivity of the fluid $\left(\mathrm{W} \cdot \mathrm{m}^{-1} \cdot \mathrm{K}^{-1}\right), u$ is the flow rate $\left(\mathrm{m} . \mathrm{s}^{-1}\right)$, and $v$ is the kinematic viscosity $\left(\mathrm{m}^{2} \cdot \mathrm{s}^{-1}\right)$

\subsection{Thermodynamic correlations}

By regressing database in HSC Chemistry software version 6.0 , correlations of the enthalpy of components and temperature were obtained as (22)-(25).

- $\mathrm{VOCl}_{3}$ liquid: $\quad h_{1}^{L}(T)=h_{1}^{\mathrm{o}, L}+150.6 T-3,762.9$

- $\mathrm{VOCl}_{3}$ vapor: $\quad h_{1}^{V}(T)=h_{1}^{\mathrm{o}, V}+94 T-2,397.8$

- $\mathrm{TiCl}_{4}$ liquid: $\quad h_{2}^{L}(T)=h_{2}^{\mathrm{o}, L}+145.8 T-3,651.1$

- $\mathrm{TiCl}_{4}$ vapor: $\quad h_{2}^{V}(T)=h_{2}^{\mathrm{o}, V}+98.8 T-2,508.3$

Units: $h-\mathrm{J} \cdot \mathrm{mol}^{-1}, T-{ }^{\circ} \mathrm{C}$.

Enthalpy of an ideal mixture was be calculated from partial molar fractions and enthalpies of pure components as (26) [14]:

$$
h=\sum f_{i} h_{i}
$$

where, $f_{i}$ is mole fraction $\left(f_{i}=x_{i}\right.$ for liquid, $f_{i}=y_{i}$ for vapor $)$.

Assuming the $\mathrm{VOCl}_{3}-\mathrm{TiCl}_{4}$ characteristic of an ideal mixture, the Raoult's law was applied for finding the relationship between the vapor mole fraction, $y_{i}$, and the liquid mole fraction, $x_{i}$, of component $i[15]$ :

$$
y_{i}=\frac{p_{i}^{*}}{P} x_{i}
$$

where, $i=1$ for $\mathrm{VOCl}_{3}$ and $i=2$ for $\mathrm{TiCl}_{4}, P$ is the operating pressure in the distillation column $(\mathrm{mmHg}), p_{i}^{*}$ is the equilibrium vapor pressure of the pure component $i$, which depends on temperature as described by the Antoine equation [16]:

$$
p_{i}^{*}(\mathrm{mmHg})=10^{A-\frac{B}{T+C}}
$$

where, $A, B, C$ are the Antoine coefficients, $C$ in ${ }^{\circ} \mathrm{C}$.

The temperature at the top of the distillation column, $T_{C}$, was considered to be equal to the boiling point of $\mathrm{VOCl}_{3}$, which was decreased by the reduction of the operating pressure according to the Clausius-Clapeyron equation [17]:

$$
T_{\mathrm{C}}=\left(\frac{1}{T_{0}}-\frac{R_{g} \ln \frac{P}{P_{0}}}{\lambda_{1}}\right)^{-1}
$$


where, $T_{0}$ is the boiling point of $\mathrm{VOCl}_{3}$ at $P_{0}=760 \mathrm{mmHg}$, $R_{\mathrm{g}}=8.314$ is the universal gas constant $\left(\mathrm{J} \cdot \mathrm{mol}^{-1} \cdot \mathrm{K}^{-1}\right), \lambda_{1}$ is the heat of vaporization of $\mathrm{VOCl}_{3}\left(\mathrm{~J}_{\mathrm{mol}} \mathrm{m}^{-1}\right)$.

Finally, the sum of the mole fractions of $\mathrm{VOCl}_{3}$ and $\mathrm{TiCl}_{4}$ in the vapor phase is unity:

$$
y_{1}+y_{2}=1
$$

\section{SOLUTION METHOD}

The numerical solution of the ordinary differential Eqns. (14) and (18) for the system was found out by applying Runge-Kutta $4^{\text {th }}$ method, using MATLAB code. Initial conditions $(t=0)$ are:

$$
\begin{gathered}
W=W_{0} \\
x_{W}=x_{W 0}
\end{gathered}
$$

Parameters of the simulation were enumerated in Appendix. As above mentioned, total heat released from condensation in the distillation column was transferred to the outer airflow. It means that the entire space in the column was at a uniform temperature. However, the bottom temperature is approx. $3^{\circ} \mathrm{C}$ higher than the top temperature in our experiment result. Therefore, $T_{C}+3$ was set as the bottom temperature of simulations.

Influences of the heating power, airflow, initial mole fraction of $\mathrm{VOCl}_{3}$, and operating pressure on the dynamic behavior of the distillation process were simulated.

\section{SIMULATION RESULTS}

Numerical solutions of the proposed models are presented in Figures 3-6 with 100 moles of the feedstock mixture, revealing the time-dependences of the $W$ and $x_{W}$. In consideration for all cases, it is observed that the bottom product, $W$, decreased with time as a linear function, indicating the constant reduction rate of the $W$ in each simulation.

Figure 3 presents the time-dependence of $W$ and $x_{W}$ with heating power $\left(Q_{0}\right)$. The slopes of lines in Figure $3 \mathrm{~A}$ confirm the faster reduction rate of the $W$ with the increase of the $Q_{0}$. Figure $3 \mathrm{~B}$ presents the decrease of the $x_{W}$ with time. For 1.8, 2 , and $2.5 \mathrm{~kW}$ of the $Q_{0}$, the $x_{W}$ tended to $2 \times 10^{-4}, 7 \times 10^{-4}$, and $3.9 \times 10^{-3}$ at 10,5 , and 2.2 hours of distillation time, respectively, when the $W$ is near to zero. This result indicates the heating power cannot improve distillation efficiency of the $\mathrm{VOCl}_{3}-\mathrm{TiCl}_{4}$ mixture.

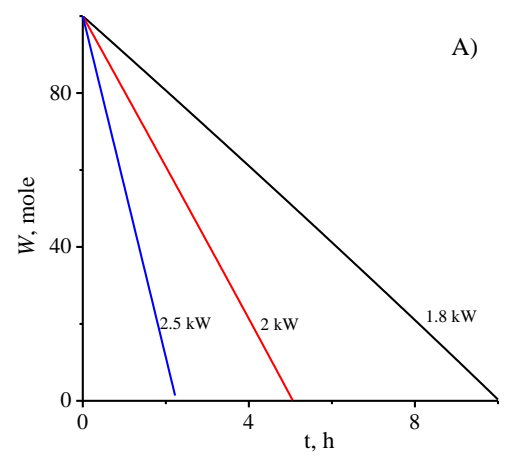

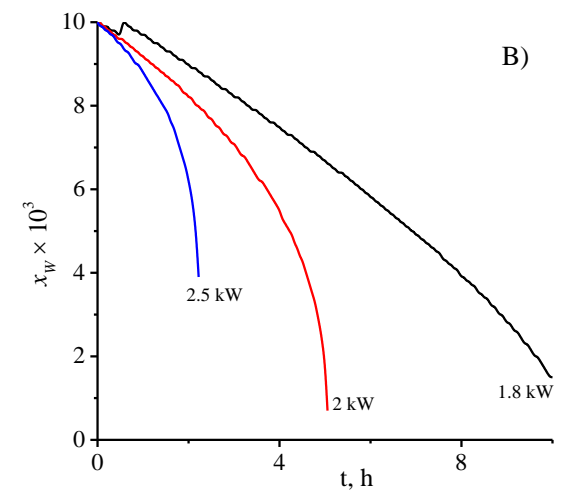

Figure 3. Effects of the heating power on time-dependence of A) $W$ and B) $x_{W}$. Conditions: $P=760 \mathrm{mmHg}, G_{\mathrm{V}}=30$ L.S ${ }^{-1}, x_{W}=0.01$
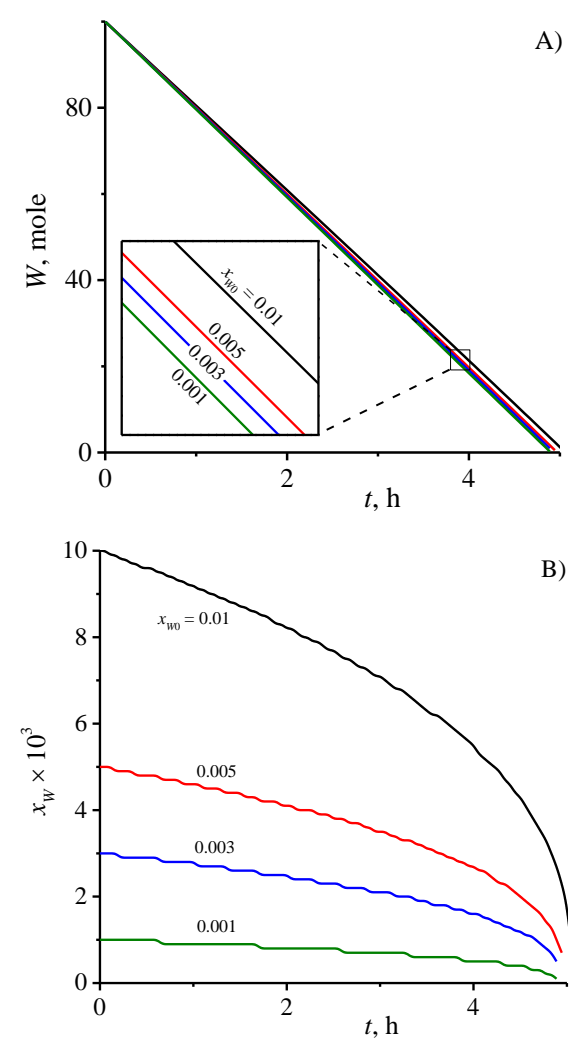

Figure 4. Effects of the initial mole fraction of $\mathrm{VOCl}_{3}$ on time-dependence of A) $W$ and B) $x_{W}$. Conditions: $P=760$ $\mathrm{mmHg}, G_{\mathrm{V}}=30 \mathrm{~L} . \mathrm{s}^{-1}, Q_{0}=2 \mathrm{~kW}$

The initial mole fraction of $\mathrm{VOCl}_{3}, x_{W 0}$, slightly influenced on the reduction rate of the $W$, as demonstrated in Figure 4A. This may be due to $x_{W 0}$ in the low range as well as the similar thermal properties of $\mathrm{VOCl}_{3}$ and $\mathrm{TiCl}_{4}$ such as heat of vaporization and boiling point (Appendix). In Figure 4B, the varieties of $x_{W}$ at different $x_{W 0}$ values are in a similar trend. $\mathrm{VOCl}_{3}$ dramatically exists in the bottom product at the end of distillation operation $(W \approx 0)$.

Figure 5 shows a strong influence of the airflow, $G_{\mathrm{V}}$, to time-dependence of the $W, x_{W}$, and air temperature. Increasing the airflow, the convective heat transfer coefficient increase, improving the condensation performance in the distillation column, resulting in the slower reduction rate of the $W$ (Figure $5 \mathrm{~A}$ ). As seen in Figure $5 \mathrm{~B}$, the mole fraction of $\mathrm{VOCl}_{3}$ in the bottom product at the end of the distillation process decreased 
with the increase of airflow. These mole fractions did not tend to zero, indicating that the airflow is not a key parameter for the pure $\mathrm{TiCl}_{4}$ recovery by distillation. However, temperature profiles (Figure 5C) of air along the distillation column significantly changed with the different set airflows. This result may be useful in considerations of mechanical design and/or safe for operators.
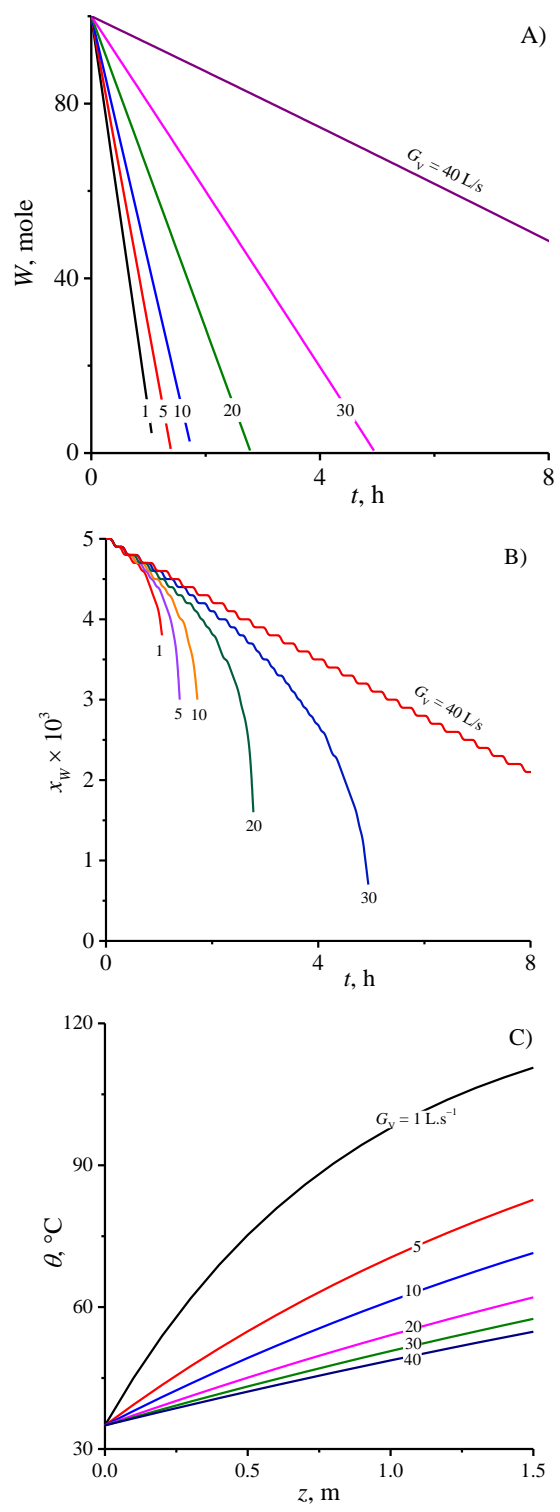

Figure 5. Effects of the airflow on time-dependence of A) $W$ and B) $x_{W}$ and C) air temperature. Conditions: $P=760$ $\mathrm{mmHg}, x_{W 0}=0.005, Q_{0}=2 \mathrm{~kW}$

The reduction rate of the $W$ increase with a decrease of the operating pressure, as shown in Figure 6A. This result is attributed to a deviation of the equilibrium state under a change of pressure [18]. At low pressure, the cross association between components in the liquid mixture is reduced, resulting in the significant distinction of equilibrium state for these components [19]. As consequently, the faster reduction of the $x_{W}$ with the lower operating pressure was observed, as shown in Figure 6B. For the operating pressure less than $360 \mathrm{mmHg}$, the $x_{W}$ reached zero before the liquid in the bottom entirely evaporated. Pure $\mathrm{TiCl}_{4}$ recovery efficiency was calculated to be around 20, 59, $84 \%$ under 360,160 , and $50 \mathrm{mmHg}$ of the operating pressure, respectively. This result indicates that distillation under vacuum conditions is possible to apply for separating the $\mathrm{VOCl}_{3}-\mathrm{TiCl}_{4}$ mixture.
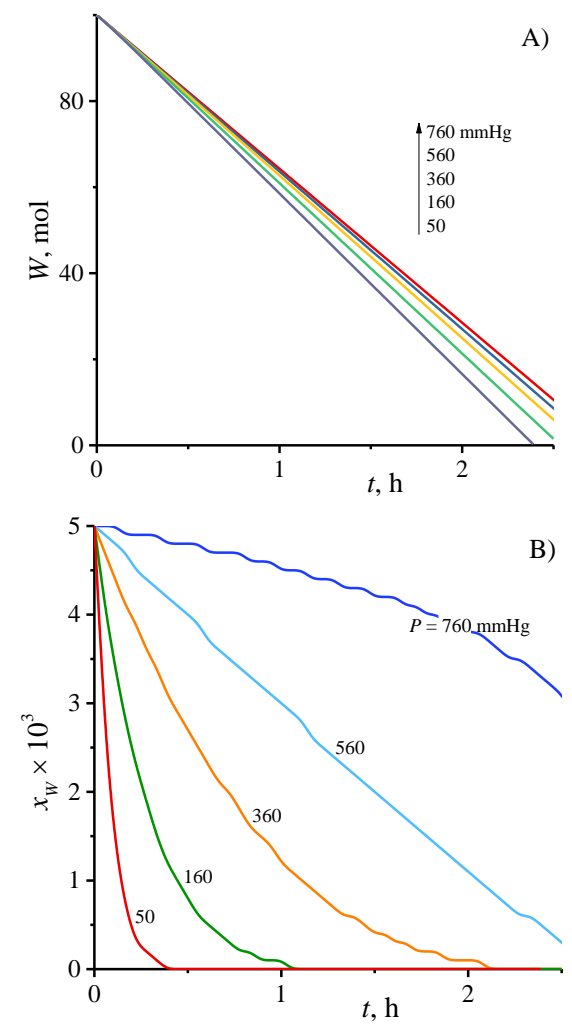

Figure 6. Effects of the operating pressure on timedependence of A) W and B) $x_{W}$. Conditions: $G_{\mathrm{V}}=30 \mathrm{~L} \cdot \mathrm{s}^{-1}$, $x_{W 0}=0.005, Q_{0}=2 \mathrm{~kW}$

\section{COMPARISON OF EXPERIMENTAL AND SIMULATED RESULTS}

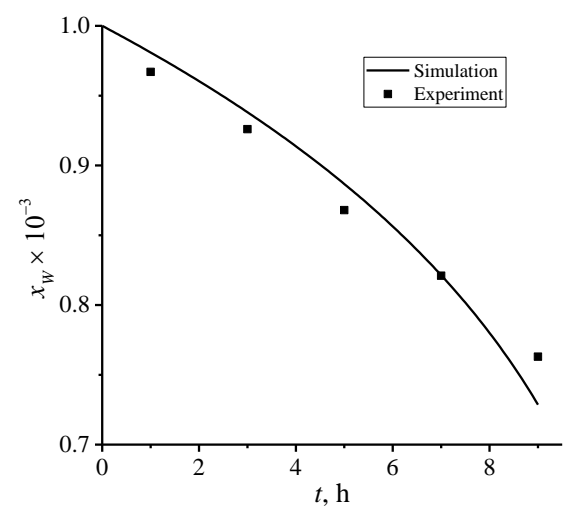

Figure 7. Time-dependence of $x_{W}$ from experiment and simulation

Obtained results from simulation were compared with experimental findings to verify the proposed models. The experiment was performed under conditions: $P=760 \mathrm{mmHg}$, $x_{W 0}=10^{-3}, Q_{0}=2 \mathrm{~kW}, G_{\mathrm{V}}=20 \mathrm{~L} \cdot \mathrm{s}^{-1}$, and $W_{0}=420$ moles. The distillation process occurred under an inert condition. The bottom liquid was sampled at different distillation times $(t=1$, $3,5,7$, and 9 hours) since the top temperature of the distillation column reached $127^{\circ} \mathrm{C}(t=0)$. $\mathrm{VOCl}_{3}$ mole fraction was calculated from vanadium content in the sample, which was 
determined by the ICP-AES technique. From Figure 7, compatibility between the simulation and the experimental results is observed. As expected, varieties of $x_{W}$ with time from experiment and simulation are in a similar trend. Deviation of the experimental values and the simulation may be due to the instinct non-ideal property of the $\mathrm{VOCl}_{3}-\mathrm{TiCl}_{4}$ system. However, the calculated relative error of the simulated results in comparison with the experimental results was less than 5\%. This indicates that the proposed models are successfully predicted the dynamic behavior of the distillation of the $\mathrm{VOCl}_{3}-\mathrm{TiCl}_{4}$ mixture.

\section{CONCLUSION}

In this paper, a simple batch distillation column for the $\mathrm{VOCl}_{3}-\mathrm{TiCl}_{4}$ mixture separation was modeled to explore the dynamic behaviors. From simulation results under different conditions, the heating power, the airflow, and the initial mole fraction of $\mathrm{VOCl}_{3}$ almost unaffected to distillation performance. However, operating pressure plays a key parameter. It was found that pure $\mathrm{TiCl}_{4}$ can be recovered by distillation under the operating pressure of less than 360 $\mathrm{mmHg}$, and the $\mathrm{TiCl}_{4}$ recovery efficiency increase as this parameter is decreased. The deviation between the simulation findings and the experimental results was also determined, that revealed a $5 \%$ of the maximum relative error. It proved that the obtained models are acceptable for the distillation simulation of the $\mathrm{VOCl}_{3}-\mathrm{TiCl}_{4}$ mixture.

\section{ACKNOWLEDGMENT}

This work was financially supported by the Vietnam Ministry of Science and Technology through the National Project coded KC.02.02/16-20.

\section{REFERENCES}

[1] Zhang, L.C., Chen LY. (2019). A review on biomedical titanium alloys: Recent progress and prospect. Advanced Engineering Materials, 21(4): 1801215. https://doi.org/10.1002/adem.201801215

[2] Schaaf, P., Kaspar, J., Höche D. (2014). Laser gasassisted nitriding of $\mathrm{Ti}$ alloys, section 9.13 in book Comprehensive Materials Processing, 9: 261-278. Amsterdam, Netherlands. https://doi.org/10.1016/B9780-08-096532-1.00912-2

[3] Veiga, C., Davim, J.P., Loureir, A.J.R. (2012). Properties and applications of titanium alloys: A brief review. Reviews on Advanced Materials Science, 32(2): 133-148.

[4] Rodriguez, M.H, Rosales, G.D., Pinna, E.G., Tunez, F.M, Toro, N (2020). Extraction of titanium from low-grade ore with different leaching agents in autoclave. Metals, 10(4): 497. https://doi.org/10.3390/met10040497

[5] Filippou, D., Hudon, G. (2020). Minerals, slags, and other feedstock for the production of titanium metal, chapter 3 in book Extractive Metallurgy of Titanium, Conventional and Recent Advances in Extraction and Production of Titanium Metal, Amsterdam, Netherlands, pp. 19-45. https://doi.org/10.1016/B978-0-12-817200$1.00003-\mathrm{X}$
[6] Jung, E.J., Kim, J., Lee, Y.R. (2021). A comparative study on the chloride effectiveness of synthetic rutile and natural rutile manufactured from ilmenite ore. Scientific Reports, 11: 4045. https://doi.org/10.1038/s41598-02183485-6

[7] Hung, L.C, Hai, T.D., Khoa, T.A, Vien, L.M., Tuan, P.D. (2019). Purification of titanium tetrachloride from titania slag chlorination. Vietnam J. Chem., 57(5): 620-627. https://doi.org/10.1002/vjch.201900105

[8] Piccolo, L., Paolinelli, A., Ghirga, M. (1976). Process for the purification of titanium tetrachloride. US. Patent No. $3,939,244$.

[9] Hockaday, L., Kale, A. (2016). Crude $\mathrm{TiCl}_{4}$ purification: A review of the current state of the art and future opportunities. The Tenth Internation Heavy Minerals Conference, Southern African Institute of Mining and Metallurgy, pp. 63-74.

[10] Rowe, L.W., Opie, W.R. (1955). Production and purification of $\mathrm{TiCl}_{4}$. JOM, 7: 1189-1193. https://doi.org/10.1007/BF03379026

[11] Gerbaud, V., Rodriguez-donis, I., Hegely, L., Lang, P., Denes, F., Xinqiang, Y. (2019). Review of extractive distillation. Process design, operation, optimization and control. Chemical Engineering Research and Design, 141: 229-271. https://doi.org/10.1016/j.cherd.2018.09.020

[12] Upreti, S.R. (2017). Process Modeling and Simulation for Chemical Engineers: Theory and Practice. Wiley, Chennai, India.

[13] Bergman, T.L., Lavine, A.S. (2017). External Flow, chapter 7 in book Fundamentals of Heat and Mass Transfer, $8^{\text {th }}$ ed. Wiley, Hoboken, USA.

[14] Sandler, S.I. (2017). The thermodynamics of multicomponent mixtures, chapter 8 in book Chemical, Biochemical, and Engineering Thermodynamics, 5th Ed. Wiley.

[15] Raoult F.M. (1886). Loi générale des tensions de vapeur des dissolvants. Comptes rendus, 104: 1430-1433.

[16] Antoine, C. (1888). Tensions des vapeurs; nouvelle relation entre les tensions et les températures. Comptes Rendus des Séances de l'Académie des Sciences (in French), 107: 681-684, 778-780, 836-837.

[17] Brown, O.L.I. (1951). The Clausius-Clapeyron Equation. J. Chem. $\quad$ Educ., 28(8): 428-429. https://doi.org/10.1021/ed028p428

[18] Guo, R.F., Zhang, L., Mo, D.M., Wu, C.M., Li, Y.R. (2021). Study on evaporation characteristics of water in annular liquid pool at low pressures. ACS Omega, 6(8): 5933-5944. https://doi.org/10.1021/acsomega.1c00134

[19] Nath, A., Bender, E. (1983). On the thermodynamics of associated solutions. III. vapor-liquid equilibria of binary and ternary systems with any number of associating components. Fluid Phase Equilibria, 10(1): 43-56. https://doi.org/10.1016/0378-3812(83)80003-X

[20] Yaws, C.L., Satyro, M.A. (2015). Vapor Pressure Inorganic Compounds, chapter 2 in the Yaws Handbook of Vapor Pressure. Antoine Coefficients, $2^{\text {nd }}$ ed. Elsevier, Oxford, UK.

[21] Haynes, W.M., Lide, D.R., Bruno, T.J. (2014). Thermochemistry, Electrochemistry, and Solution Chemistry, chapter 5 in CRC Handbook of Chemistry and Physics, 95th ed. CRC Press, Boca Raton, US.

[22] Haynes, W.M., Lide, D.R., Bruno, T.J. (2014). Fluid Properties, chapter 6 in CRC Handbook of Chemistry and Physics, 95th ed. CRC Press, Boca Raton, US. 


\begin{tabular}{|c|c|c|c|c|}
\hline \multicolumn{2}{|r|}{ Parameters } & Symbol & Value & Ref. \\
\hline \multicolumn{5}{|c|}{ Design and operation parameters } \\
\hline & Height $(\mathrm{m})$ & $H$ & 1.5 & \\
\hline & Inner diameter (m) & $R$ & 0.15 & \\
\hline & Outer diameter $(\mathrm{m})$ & $R_{0}$ & 0.2 & \\
\hline & Feedstock (mole) & $W_{0}$ & 100 & \\
\hline & Temperature of inlet air $\left({ }^{\circ} \mathrm{C}\right)$ & $\theta_{\mathrm{n}}$ & 35 & \\
\hline \multicolumn{5}{|c|}{ Properties of pure components } \\
\hline \multirow{7}{*}{$\mathrm{VOCl}_{3}$} & & $A_{1}$ & 7.02483 & [20] \\
\hline & Antoine coefficients & $B_{1}$ & 1518.94 & [20] \\
\hline & & $C_{1}$ & 239.69 & [20] \\
\hline & Standard enthalpy of vapor (J.mol $\left.{ }^{-1}\right)$ & $h_{1}^{\mathrm{o}, V}$ & -695.6 & [21] \\
\hline & Standard enthalpy of liquid (J.mol $\left.{ }^{-1}\right)$ & $h_{1}^{\mathrm{o}, L}$ & -734.7 & [21] \\
\hline & Heat of vaporization $\left(\mathrm{J} . \mathrm{mol}^{-1}\right)$ & $\lambda_{1}$ & 36.78 & [21] \\
\hline & Boiling point at $760 \mathrm{mmHg}\left({ }^{\circ} \mathrm{C}\right)$ & $T_{0}$ & 127 & [22] \\
\hline \multirow{6}{*}{$\mathrm{TiCl}_{4}$} & & $A_{2}$ & 7.295 & [20] \\
\hline & Antoine coefficients & $B_{2}$ & 1668.82 & [20] \\
\hline & & $C_{2}$ & 242.2 & [20] \\
\hline & Standard enthalpy of liquid $\left(\mathrm{kJ} . \mathrm{mol}^{-1}\right)$ & $h_{2}^{\mathrm{o}, L}$ & -804.2 & [21] \\
\hline & Heat of vaporization $\left(\mathrm{kJ} . \mathrm{mol}^{-1}\right)$ & $\lambda_{2}$ & 36.2 & [22] \\
\hline & Boiling point at $760 \mathrm{mmHg}\left({ }^{\circ} \mathrm{C}\right)$ & & 136.5 & [22] \\
\hline \multicolumn{4}{|c|}{ Properties of air at $40^{\circ} \mathrm{C}, 1 \mathrm{~atm}$} & [13] \\
\hline & Thermal conductivity $\left(\mathrm{W} \cdot \mathrm{m}^{-1} \cdot \mathrm{K}^{-1}\right)$ & $k$ & $26.62 \times 10^{-3}$ & \\
\hline & Kinematic viscosity $\left(\mathrm{m}^{2} \cdot \mathrm{s}^{-1}\right)$ & $v$ & $1.702 \times 10^{-5}$ & \\
\hline & Density $\left(\mathrm{kg} \cdot \mathrm{m}^{-3}\right)$ & $\rho$ & 1.127 & \\
\hline Cons & tant pressure heat capacity $\left(\mathrm{J} \cdot \mathrm{kg}^{-1} \cdot \mathrm{K}^{-1}\right)$ & $c_{p, a}$ & 1007 & \\
\hline & Prandtl number & $\operatorname{Pr}$ & 0.7255 & \\
\hline
\end{tabular}

